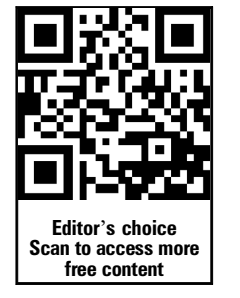

${ }^{1}$ Surveillance Branch, Division of Respiratory Disease Studies, National Institute for

Occupational Safety and Health, Centers for Disease Control and Prevention, Morgantown,

West Virginia, USA

${ }^{2}$ Epidemic Intelligence Service Program, Division of Scientific Education and Professional Development, Centers for

Disease Control and Prevention, Atlanta, Georgia, USA

\section{Correspondence to} Dr David I Blackley, Surveillance Branch, Division of Respiratory Disease Studies, National Institute for Occupational Safety and Health, Centers for Disease Control and Prevention, 1095 Willowdale Rd. Mail Stop HG900, Morgantown, WV 26505-2888, USA; dblackley@cdc.gov

Received 12 March 2014 Revised 20 June 2014 Accepted 3 July 2014 Published Online First 22 July 2014

\title{
Small mine size is associated with lung function abnormality and pneumoconiosis among underground coal miners in Kentucky, Virginia and West Virginia
}

\author{
David J Blackley, ${ }^{1,2}$ Cara N Halldin, ${ }^{1}$ Mei Lin Wang, ${ }^{1}$ A Scott Laney ${ }^{1}$
}

\section{ABSTRACT \\ Objectives To describe the prevalence of lung function abnormality and coal workers' pneumoconiosis (CWP) by mine size among underground coal miners in Kentucky, Virginia and West Virginia. \\ Methods During 2005-2012, 4491 miners completed spirometry and chest radiography as part of a health surveillance programme. Spirometry was interpreted according to American Thoracic Society and European Respiratory Society guidelines, and radiography per International Labour Office standards. Prevalence ratios (PR) were calculated for abnormal spirometry (obstructive, restrictive or mixed pattern using lower limits of normal derived from National Health and Nutrition Examination Survey (NHANES) III) and CWP among workers from small mines ( $\leq 50$ miners) compared with those from large mines.}

Results Among 3771 eligible miners, those from small mines were more likely to have abnormal spirometry (18.5\% vs $13.8 \%, p<0.01)$, CWP $(10.8 \%$ vs $5.2 \%$, $\mathrm{p}<0.01)$ and progressive massive fibrosis $(2.4 \%$ vs $1.1 \%, p<0.01)$. In regression analysis, working in a small mine was associated with 37\% higher prevalence of abnormal spirometry (PR 1.37, 95\% Cl 1.16 to 1.61 ) and 2.1 times higher prevalence of CWP $(95 \% \mathrm{Cl} 1.68$ to 2.70).

Conclusions More than one in four of these miners had evidence of CWP, abnormal lung function or both. Although $96 \%$ of miners in the study have worked exclusively under dust regulations implemented following the 1969 Federal Coal Mine Safety and Health Act, we observed high rates of respiratory disease including severe cases. The current approach to dust control and provision of safe work conditions for central Appalachian underground coal miners is not adequate to protect them from adverse respiratory health effects.

\section{INTRODUCTION}

Following decades of decline, the prevalence of coal workers' pneumoconiosis (CWP) among active US underground coal miners has been increasing since the late 1990 s. $^{1-3}$ Data from miners participating in the National Institute for Occupational Safety and Health (NIOSH)-administered Coal Workers' Health Surveillance Program (CWHSP) suggest that the current prevalence of CWP among underground miners with long mining tenures is approximately double its 1995-1999 low point. The prevalence of

\section{What this paper adds}

Current knowledge

- Inhalation of coal mine dust causes coal workers' pneumoconiosis (CWP) and other diseases affecting lung function. The prevalence of CWP among US coal miners has doubled since the late 1990s. Previously, small mine size ( $\leq 50$ employees) was associated with increased risk of CWP, but it is unclear whether mine size is associated with risk of abnormal lung function.

\section{What we found}

- Compared with large mines, working in a small mine in Kentucky, Virginia or West Virginia was associated with a higher prevalence of abnormal lung function and CWP.

Public health significance

- This is the first report on the prevalence of lung function abnormality by mine size, and the first update on the prevalence of CWP by mine size since NIOSH began targeted outreach to workers from small mines.

- Modern approaches to dust control provide inadequate protection for a large portion of US underground coal miners.

progressive massive fibrosis (PMF), the severe form of CWP, has more than quadrupled since the 1980 s among central Appalachian underground coal miners. ${ }^{4} 5$ Currently, nearly all active coal miners with CWP have worked exclusively under dust standards implemented following the Federal Coal Mine Health and Safety Act of 1969, suggesting that miners still lack adequate protection from coal mine dust (CMD)-related disease. ${ }^{6}$

Hypothesised factors contributing to increases in CWP prevalence include changes in mining practices, inadequate enforcement of current dust standards, longer work hours and increased exposure to crystalline silica. ${ }^{7}$ Recognition of geographic clusters of rapidly progressive CWP, most notably in Kentucky, Virginia and West Virginia, indicates that this region may shoulder a disproportionate burden of disease. ${ }^{9}$ Identification of these clusters was an important step, but it remains unclear as to what underlying factors are driving CWP disparities. Mine size (number of underground miners 
employed) has recently been identified as a predictor of CWP risk among US underground coal miners. ${ }^{10-12}$ As a result, NIOSH has used targeted surveillance to focus on workers from small underground mines. ${ }^{13}$

The Enhanced CWHSP (ECWHSP) was started in 2005 by NIOSH in collaboration with the Mine Safety and Health Administration (MSHA). The original objectives of the ECWHSP were to target regions with clustering of rapidly progressive CWP and low participation in the Coal Workers' X-ray Surveillance Program (CWXSP), an existing component of the CWHSP. ${ }^{13}$ Miners participating in ECWHSP provide occupational histories, and are offered spirometry, a measure of lung function, in addition to a chest radiograph. Spirometry data are an important addition to the surveillance programme because exposure to CMD has been linked to lung function impairment, which can cause substantial morbidity independent of radiographic evidence of CWP. ${ }^{14-16}$ In the absence of biomarkers for CWP, spirometric testing can complement chest radiography as a useful tool to help clinicians monitor the health status of coal miners, perhaps enhancing the potential for intervention to preserve respiratory health. ${ }^{6} 17$ The goal of this study is to characterise the prevalence of lung function abnormality and CWP by mine size among active underground coal miners working in Kentucky, Virginia and West Virginia.

\section{METHODS}

\section{Participants}

Analysis was restricted to active underground coal miners participating in the ECWHSP during September 2005-December 2012. Although the ECWHSP targeted geographic regions using the aforementioned criteria, all coal miners, current and former, were welcome to be screened at the mobile unit. As of December 2012, ECWHSP had participants from 15 states, but we restricted analysis to Kentucky, Virginia and West Virginia because of the limited sample size $(n=254)$ from small mines outside these three states. ECWHSP is a surveillance programme with non-research designation, and is exempt from $\mathrm{NIOSH}$ Human Subjects Review Board approval (11-DRDS-NR03). Prior to screening, participants signed a consent form acknowledging their confidential participation in a health surveillance programme. For miners with multiple ECWHSP encounters, only the most recent visit was used.

\section{Chest radiography and spirometry testing}

Chest radiographs and spirometry were administered by trained technicians in a NIOSH mobile examination unit. Radiographs were interpreted by a minimum of two NIOSH-approved physician B Readers, ${ }^{18}$ and lung parenchymal abnormalities consistent with CWP were classified using the International Labour Office (ILO) Guidelines for the Use of the ILO International Classification of Radiographs of Pneumoconioses. ${ }^{19}$ Presence of CWP was defined as profusion of small pneumoconiotic opacities ILO subcategory $1 / 0$ or above (possible range: $0 / 0-3 /+$ ), and PMF was defined as the presence of large $(>1 \mathrm{~cm})$ pneumoconiotic opacities (category A, B or C). ${ }^{19}$

Spirometry was administered by NIOSH-trained technicians using a dry-rolling seal spirometer and interpreted using American Thoracic Society and European Respiratory Society guidelines. ${ }^{20} 21$ Lower limits of normal (LLN) for forced expiratory volume in $1 \mathrm{~s}$ $\left(\mathrm{FEV}_{1}\right)$, forced vital capacity (FVC), and the ratio $\mathrm{FEV}_{1} / \mathrm{FVC}$, which characterises the proportion of the miner's vital capacity expelled in the first second of expiration, were calculated using sex and race/ethnicity-specific prediction equations derived from data collected during the Third National Health and Nutrition
Examination Survey (NHANES). ${ }^{22}$ Per cent predicted values for FEV1 and FVC were also calculated. Patterns of abnormality were defined as obstructive, restrictive or mixed, as follows ${ }^{23}$ :

Obstructive pattern: $\mathrm{FEV}_{1} / \mathrm{FVC}<\mathrm{LLN}$; and $\mathrm{FVC}>\mathrm{LLN}$; and $\mathrm{FEV}_{1}<\mathrm{LLN}$

Restrictive pattern: $\mathrm{FEV}_{1} / \mathrm{FVC}>\mathrm{LLN}$; and FVC $<\mathrm{LLN}$

Mixed pattern: $\mathrm{FEV}_{1} / \mathrm{FVC}<\mathrm{LLN}$; and $\mathrm{FVC}<\mathrm{LLN}$

Abnormal lung function, as an analytic outcome variable in the following analysis, is defined as the presence of one of the above three patterns.

Miner demographics, underground mining tenure, smoking status (defined as a miner reporting ever being a smoker) and body mass index (BMI) were calculated using data provided by the miner in the mobile examination unit. Mining plans submitted by mines to MSHA were used to determine the number of underground miners by location for the year the miner participated in the ECWHSP. For consistency with earlier work, mines with 50 or fewer underground employees were classified as 'small' and those with more than 50 were classified as 'large'. ${ }^{10}$

\section{Statistical analysis}

Data were analysed using SAS V.9.3 (SAS Institute, Cary, North Carolina, USA). Crude comparisons of worker characteristics by mine size were assessed using the $\chi^{2}$ test (for dichotomous variables) and the $t$ test (for continuous variables). Log-binomial regression models with response variables characterising abnormal lung function and CWP status were fit to ECWHSP data. These models allowed unbiased estimation of adjusted prevalence ratios (PR) for abnormal spirometry and a determination of CWP among those working in small mines, compared with counterparts in large mines. ${ }^{24} 25$

\section{RESULTS}

\section{Descriptive characteristics}

From September 2005 to December 2012, 8980 underground miners completed visits to the ECWHSP mobile unit; 4491 of these worked in Kentucky, Virginia or West Virginia. After excluding former miners, miners with fewer than two acceptable spirometry curves indicating maximum effort, and duplicate observations (ie, those with more than one ECWHSP encounter during the time period), 3771 remained. Less than $3 \%$ of the otherwise eligible sample was excluded due to invalid spirometry results. The 3771 miners ranged from 18 to 74 years of age. The mean and median mine sizes were 200 and 97 employees, respectively. Descriptive characteristics are summarised in table 1 . There was no statistically significant difference $(\alpha=0.05)$ between those working in small mines and those in large mines by sex, race or underground mining tenure. Those from large mines were on average 1 year older, and had a slightly higher BMI. Those from small mines were more likely to report ever smoking.

\section{Spirometry results}

A total of $551(14.6 \%)$ miners had abnormal (obstructive, restrictive or mixed pattern) spirometry results (table 2). The overall prevalence of abnormal spirometry was higher among workers from small mines $(18.5 \%$ vs $13.4 \%)$. Those from small mines had significantly higher prevalence of obstructive and mixed abnormalities, but there was no significant difference by mine size among those with a restrictive abnormality. Mean 
Table 1 Demographics and characteristics of active underground Kentucky, Virginia and West Virginia coal miners participating in Enhanced Coal Workers' Health Surveillance Program (ECWHSP), September 2005 to December 2012, n=3771

\begin{tabular}{lllr}
\hline Characteristics & $\begin{array}{l}\text { Small mine } \\
(\mathbf{n}=908)\end{array}$ & $\begin{array}{l}\text { Large mine } \\
(\mathbf{n}=2863)\end{array}$ & \multicolumn{1}{c}{$\begin{array}{l}\mathbf{p} \\
\text { Value }\end{array}$} \\
\hline Sex, n male (\%) & $906(99.8)$ & $2849(99.5)$ & 0.44 \\
Race, n white (\%) & $901(99.2)$ & $2820(98.6)$ & 0.09 \\
Ever smoker (\%) & $507(56.1)$ & $1409(49.4)$ & $<0.01$ \\
Age, mean (SD) & $45.8(10.4)$ & $46.8(10.5)$ & 0.02 \\
UG tenure, mean (SD) & $20.9(11.6)$ & $21.0(12.0)$ & 0.73 \\
BMI, mean (SD) & $29.9(5.2)$ & $30.3(5.0)$ & 0.04 \\
\hline
\end{tabular}

BMI, body mass index; $n$, number; UG, underground.

$\mathrm{FEV}_{1} / \mathrm{FVC}$ and per cent predicted values for $\mathrm{FEV}_{1}$ and FVC were lower among workers from small mines.

\section{Chest radiograph results}

Radiographic evidence of CWP was found in 6.5\% $(n=246)$ of miners screened; 53 (1.4\%) had PMF. The prevalence of CWP was higher among workers from small mines $(10.8 \%$ vs $5.2 \%$, table 2). Examining the data by small opacity profusion category, there were significant differences in prevalence by mine size for categories 1 and 2, but not category 3. The prevalence of PMF was also higher among those from small mines $(2.4 \%$ vs $1.1 \%)$.

\section{Adjusted results}

Abnormal spirometry

Table 2 includes results from log-binomial regression models with spirometry results (normal/abnormal) as the binary response. Controlling for underground mining tenure, BMI and smoking status, working in a small mine was associated with $37 \%$ higher prevalence of abnormal spirometry compared with working in a large mine (PR 1.37, 95\% CI 1.16 to 1.61).

Miner age and underground mining tenure are known factors associated with CWP. Because age and mining tenure are highly correlated, simultaneous inclusion of these variables in multiple regression models could lead to model instability due to multicollinearity. Because the ECWHSP collects high-quality work histories, PRs presented here are tenure adjusted. However, when testing the impact of using age instead of underground tenure during model development, the adjusted PR for those from small mines changed minimally, suggesting that the overall magnitude of effect does not hinge greatly on whether age or tenure is used.

\section{Presence of CWP}

The association between mine size and presence of CWP is summarised in table 2. Controlling for underground mining tenure and smoking status, those working in small mines were two times more likely to have CWP than those in large mines (PR $2.13,95 \%$ CI 1.68 to 2.70$)$. Substituting age in place of underground mining tenure resulted in minimal change to adjusted effect sizes.

\section{Concurrent abnormal spirometry and CWP}

Of the 246 miners with CWP, 75 (30.5\%) had abnormal spirometry, compared with 476 of $3525(13.5 \%)$ miners without CWP. Thus, the prevalence of abnormal spirometry among those with radiographic evidence of CWP was 2.3 times higher than among those without CWP $(p<0.01)$. Compared with those from large mines, workers from small mines had 2.5 times higher prevalence of concurrent abnormal spirometry and a determination of CWP (PR 2.48, 95\% CI 1.58 to 3.88, figure 1$)$. Less than $1 \%(31 /$

Table 2 Spirometry and chest radiograph results among active underground Kentucky, Virginia, and West Virginia coal miners participating in Enhanced Coal Workers' Health Surveillance Program (ECWHSP), by mine size, September 2005-December 2012, n=3771

\begin{tabular}{|c|c|c|c|c|}
\hline & Small mine $(n=908)$ & Large mine $(n=2863)$ & Effect measure* & $95 \% \mathrm{Cl}$ \\
\hline \multicolumn{5}{|l|}{ Spirometry } \\
\hline Abnormal, n (\%) & $168(18.5)$ & $383(13.4)$ & 1.38 & 1.17 to 1.62 \\
\hline Obstructive† & $61(6.7)$ & $132(4.6)$ & 1.46 & 1.09 to 1.96 \\
\hline Restrictive & $84(9.3)$ & $214(7.5)$ & 1.24 & 0.97 to 1.58 \\
\hline Mixed & $23(2.5)$ & $37(1.3)$ & 1.96 & 1.17 to 3.28 \\
\hline$\%$ pred $\mathrm{FEV}_{1}$, mean (SD) & $92.60(15.2)$ & $95.24(14.1)$ & -2.64 & -1.52 to -3.76 \\
\hline$\%$ pred FVC & $96.39(13.0)$ & $97.68(12.4)$ & -1.30 & -0.33 to -2.26 \\
\hline $\mathrm{FEV}_{1} / \mathrm{FVC}$ & $75.53(8.4)$ & $76.49(7.5)$ & -0.97 & -0.35 to -1.58 \\
\hline \multicolumn{5}{|l|}{ ILO classification } \\
\hline CWP, n (\%) & $98(10.8)$ & $148(5.2)$ & 2.09 & 1.64 to 2.67 \\
\hline Category $1 \ddagger$ & $69(7.6)$ & 97 (3.4) & 2.24 & 1.66 to 3.03 \\
\hline Category 2 & $25(2.8)$ & $38(1.3)$ & 2.07 & 1.26 to 3.42 \\
\hline Category 3 & $4(0.4)$ & $13(0.5)$ & 0.97 & 0.32 to 2.97 \\
\hline PMF, n (\%) & $22(2.4)$ & $31(1.1)$ & 2.24 & 1.30 to 3.85 \\
\hline \multicolumn{5}{|l|}{ Adjusted results } \\
\hline Abnormal spirometry & & & 1.37 & 1.16 to 1.61 \\
\hline CWP & & & 2.13 & 1.68 to 2.70 \\
\hline
\end{tabular}




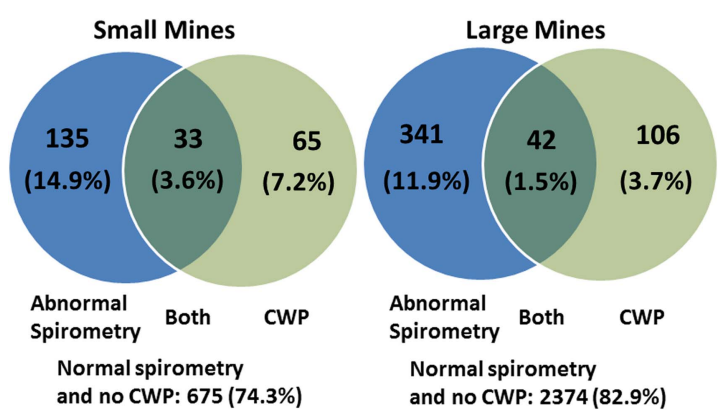

Figure 1 The relationship between abnormal spirometry and radiographic evidence of coal workers' pneumoconiosis among Kentucky, Virginia, and West Virginia underground coal miners, by mine size, Enhanced Coal Workers' Health Surveillance Program (ECWHSP), September 2005-December 2012.

3696) of miners had PMF in the absence of abnormal spirometry, while $29.3 \%(22 / 75)$ of miners with abnormal spirometry and CWP were found to have PMF.

\section{DISCUSSION}

To the best of our knowledge, this is the first study to characterise the prevalence of abnormal lung function among coal miners with respect to mine size. Previous work documented a high prevalence of CWP among coal miners working in small mines, but this was prior to NIOSH's surveillance focus on 'hot spots' and areas where small mines predominate. ${ }^{9} 1012$ Although we focused on three states, these results are generally consistent with findings from earlier work examining the association between mine size and CWP; we incorporated additional data from targeted surveillance and used regression methods to estimate adjusted PR.

Within Kentucky, Virginia and West Virginia, the prevalence of abnormal spirometry was about $40 \%$ higher among workers from small mines, after controlling for tenure, BMI and smoking status. Exposure to CMD, high BMI and smoking have been associated with declines in $\mathrm{FEV}_{1}$ among US underground coal miners. ${ }^{26}$ We were able to account for differences in BMI and smoking, but did not have measured exposure data for CMD. As will be discussed later, it is likely that CMD levels are higher in small mines. Unmeasured factors, such as history of childhood pneumonia, passive exposure to tobacco smoke, and exposure to coal or wood smoke in the home, are also associated with declines in lung function. ${ }^{26}$ Although it is possible that these factors differ among workers based on mine size, they are unlikely explanations for the observed differences. In a longitudinal study, Wang et $a l^{26}$ noted a tendency among workers in small mines to have higher rates of $\mathrm{FEV}_{1}$ decline over an average of 11 years, but the study had limited power $(n=264)$ and the difference was not significant. Although ECWHSP data are not longitudinal, this large sample within Kentucky, Virginia and West Virginia allows for prevalence estimates with improved precision.

We observed a clear negative association between mine size and the prevalence of CWP. These findings are consistent with those reported by Laney and Attfield in 2010, although they analysed CWXSP and ECWHSP data through 2009, prior to the ECWHSP's focus on small mines. ${ }^{10}$ Differences in work practices and conditions leading to elevated CMD levels may be associated with mine size, which could explain part of the relationship observed here. In addition, the practice of thin-seam mining is common in Kentucky, Virginia and West Virginia and it has been documented that thin seam mining involves drilling through more quartz-bearing rock. ${ }^{27}$ As a result, miners are at risk for exposure to high concentrations of respirable crystalline silica in airborne dust. It may be that workers in these small mines are exposed to relatively more CMD including more silica dust as a result of differences in geological conditions, equipment maintenance resources, work practices and ventilation controls.

For a disease like CWP, which is irreversible and often difficult to identify, any practical means of early detection would be a valuable tool for miners and their clinicians. Among coal miners, periodic spirometry is recommended. ${ }^{14}$ Rapid lung function declines have recently been documented among young miners progressing to $\mathrm{PMF}^{28}$ While we observed a relatively low proportion of miners with abnormal spirometry results to also have CWP, a high proportion of miners who did have concurrent abnormalities were diagnosed with PMF, the most severe form of pneumoconiosis.

Individuals with chronic obstructive pulmonary disease (COPD) often experience lung function impairment. Cigarette smoking is the most common risk factor for COPD and the prevalence of lung function impairment is three times higher among current smokers compared with non-smokers. ${ }^{29}$ History of smoking is common within the mining sector, ${ }^{30}$ but COPD can also result from exposure to CMD, even among non-smokers and in the absence of radiographic evidence of simple CWP. ${ }^{14}$ We found $14.9 \%$ of small mine workers and $11.9 \%$ of large mine workers to have abnormal spirometry but no radiographic evidence of CWP. Even with limited efficacy as an early detection tool for simple CWP, periodic spirometry among coal miners could still play an important role in monitoring their respiratory health.

Participation in the ECWHSP is voluntary, which could introduce selection factors. A recent analysis found no evidence of positive bias in the reported prevalence of CWP due to trends in NIOSH surveillance programme participation, even after addition of the ECWHSP to the existing CWXSP. ${ }^{31}$ The authors found that, if anything, NIOSH underestimates the prevalence of CWP among US underground coal miners. Owing to a small sample of active underground coal miners outside Kentucky, Virginia, and West Virginia, we limited analysis to these three states, and findings may not be generalisable to small mines in other regions. However, current ECWHSP plans include an intensified focus on recruitment from small underground coal mines throughout the country to address this issue. We used underground mining tenure as a surrogate for dust exposure. Because CMD is the only cause of CWP, direct exposure ascertainment would be ideal, but it was not possible in the current study. A final rule recently issued by MSHA will require, by 2016, the use of continuous personal dust monitors to assess exposures of underground coal miners in positions exposed to the highest respirable dust concentrations in addition to miners with evidence of pneumoconiosis. ${ }^{32}$ Unlike CWP, lung function impairment has multiple causes. Therefore, it is difficult to determine the proportion of the abnormalities observed among this particular population attributable to occupational exposures. The study was cross-sectional, and although unlikely, we cannot rule out the possibility that a portion of the observed small mine effect may be attributable to large mine operators' ability to identify and exclude miners with pre-existing lung function deficits or pneumoconiosis during pre-employment screening. The choice of 50 underground employees for the 'small' mine size cut-off is arguable. The lower quartile values of mine size for the entire sample and for CWP cases closely bound 50. Given the distribution of these data and the 
precedent established by previous research, we felt this cut-off was appropriate and practically meaningful, and that it would allow us to compare our findings to past work. Developing an ordinal or continuous predictor could be useful for future research on the mine size effect.

Practically all miners (>96\%) included in this study have worked exclusively under CMD regulations established by the 1969 Coal Mine Health and Safety Act. Coal mining is a physically demanding profession, yet more than 19\% of those screened had CWP, abnormal lung function or both. A significantly higher burden of respiratory disease was observed among workers from small mines. Mining practices have changed over time, and environmental and/or work-practice differences between small and large mines could influence exposure characteristics.

Within the context of what is now known about the resurgence of CWP and PMF in central Appalachia, these most recent findings are troubling, especially considering that PMF was nearly eliminated from the region during the 1990s. ${ }^{5}$ The current prevalence and severity of respiratory illness among underground coal miners in central Appalachia is high compared with available historical standards, and the picture among workers in the smallest mines is even worse. There is no published standard with which to directly compare these lung function findings, but the realisation that $15 \%$ of this relatively young and working population had a spirometric abnormality is cause for scrutiny. A key component of the recent MSHA rule will soon require incorporation of lung function testing into all NIOSH coal miner (underground and surface) respiratory health surveillance activities. ${ }^{32}$ These results remind us that this remains an important public health problem more than four decades after enforceable dust limits were implemented, and suggest that for miners in certain portions of the industry, the burden of debilitating respiratory disease is currently higher than national and regional levels from 10, 20 or even 30 years ago. If implemented effectively, the protections outlined in MSHA's rule to lower miners' exposure to respirable dust represent historic and welcome progress in the effort to safeguard the health of US coal miners.

Acknowledgements The authors would like to acknowledge the work of Anita Wolfe and the Coal Workers' Health Surveillance Program staff. The authors also to thank Dr. Lu-Ann Beeckman-Wagner for assistance with spirometry data quality review and interpretation.

Contributors DJB designed the study, analysed and interpreted the data, led writing of the article and takes responsibility for its content. CNH assisted with statistical software coding, analysing and interpreting data and writing the article. MLW assisted with study design, data interpretation and article revisions. ASL helped with study conceptualisation and design, data interpretation and writing the article.

Competing interests None.

Disclaimer The findings and conclusions in this report are those of the authors and do not necessarily represent the views of the National Institute for Occupational Safety and Health or the Centers for Disease Control and Prevention.

Provenance and peer review Not commissioned; externally peer reviewed.

\section{REFERENCES}

1 Graber JM, Cohen RA, Miller BG, et al. Increased morbidity and mortality among coal workers: lessons learned from well-designed epidemiological research programmes. In: Venables K, ed. Current topics in occupational epidemiology. Oxford University Press, 2013:3-16.

2 National Institute for Occupational Safety and Health. Coal Workers' Pneumoconiosis: Morbidity, Work-Related Lung Disease Surveillance System (eWoRLD) 2011.

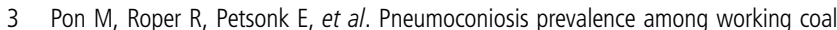
miners examined in federal chest radiograph surveillance programs-United States, 1996-2002. MMWR Morb Mortal Wkly Rep 2003;52:336-40.
4 Attfield M, Hale J, Suarthana E, et al. Current intelligence bulletin 64: coal mine dust exposures and associated health outcomes - a review of information published since 1995. Cincinnati, OH: U.S. Department of Health and Human Services, Centers for Disease Control and Prevention, National Institute for Occupational Safety and Health; 2011:38. DHHS (NIOSH) Publication No. 2011-172.

5 Laney AS, Petsonk EL, Attfield MD. Pneumoconiosis among underground bituminous coal miners in the United States: is silicosis becoming more frequent? Occup Environ Med 2010;67:652-6.

6 Petsonk EL, Rose C, Cohen R. Coal mine dust lung disease. New lessons from old exposure. Am J Respir Crit Care Med 2013;187:1178-85.

7 Antao V, Petsonk E. Advanced cases of coal workers' pneumoconiosis-two counties, Virginia, 2006. MMWR Morb Mortal Wkly Rep 2006;55:909-13.

8 Attfield M, Petsonk E. Advanced pneumoconiosis among working underground coal miners-Eastern Kentucky and Southwestern Virginia, 2006. MMWR Morb Mortal Wkly Rep 2007;56:652-5.

9 Antao VC, Petsonk EL, Sokolow LZ, et al. Rapidly progressive coal workers' pneumoconiosis in the United States: geographic clustering and other factors. Occup Environ Med 2005;62:670-4.

10 Laney AS, Attfield MD. Coal workers' pneumoconiosis and progressive massive fibrosis are increasingly more prevalent among workers in small underground coal mines in the United States. Occup Environ Med 2010;67:428-31.

11 Laney AS, Petsonk EL, Hale JM, et al. Potential determinants of coal workers' pneumoconiosis, advanced pneumoconiosis, and progressive massive fibrosis among underground coal miners in the United States, 2005-2009. Am J Public Health 2012;102:S279-83.

12 Suarthana E, Laney A, Storey E, et al. Coal workers' pneumoconiosis in the United States: regional differences 40 years after implementation of the 1969 Federal Coal Mine Health and Safety Act. Occup Environ Med 2011;68:908-13.

13 National Institute for Occupational Safety and Health. Enhanced Coal Workers' Health Surveillance Program (ECWHSP), 2011.

14 National Institute for Occupational Safety and Health. Criteria for a recommended standard, occupational exposure to respirable coal mine dust. Cincinnati, $\mathrm{OH}$ : NIOSH Publications Dissemination; 1995. (DHHS) NIOSH Publication No. 95-106.

15 Cohen R, Patel A, Green F. Lung disease caused by exposure to coal mine and silica dust. Semin Respir Crit Care Med 2008;29:651-61.

16 Beeckman L, Wang M, Wagner G, et al. Accelerated declines in FEV1 and subsequent increased respiratory symptoms, illnesses, and mortality in coal miners. Am J Respir Crit Care Med 2001;163:633-9.

17 Gulumian P, Borm P, Vallyathan V, et al. Mechanistically identified suitable biomarkers of exposure, effect, and susceptibility for silicosis and coal workers' pneumoconiosis: a comprehensive review. J Toxicol Env Heal B 2006;9:357-95.

18 National Institute for Occupational Safety and Health. The NIOSH B Reader Program 2011.

19 International Labour Office. Guidelines for the use of the ILO International Classification of Radiographs of Pneumoconioses. Geneva, Switzerland: International Labour Office, 2002.

20 Miller M, Hankinson J, Brusasco V, et al. Standardisation of spirometry. Eur Respir J 2005:26:319-38.

21 Pellegrino R, Viegi G, Brusasco V, et al. Interpretive strategies for lung function tests. Eur Respir J 2005;26:948-68.

22 Hankinson J, Odencrantz J, Fedan K. Spirometric reference values from a sample of the general U.S. population. Am J Respir Crit Care Med 1999;159:179-87.

23 Wang $M$, Beeckman-Wagner L, Wolfe $A$, et al. Lung-function impairment among US underground coal miners, 2005 to 2009. J Occup Environ Med 2013:55:846-50

24 McNutt L, Wu C, Xue $X$, et al. Estimating the relative risk in cohort studies and clinical trials of common outcomes. Am J Epidemiol 2003;157:940-3.

25 Zocchetti $C$, Consonni D, Bertazzi PA. Estimation of prevalence rate ratios from cross-sectional data. Int J Epidemiol 1995;24:1064-5.

26 Wang M, Petsonk E, Beeckman L, et al. Clinically important FEV1 declines among coal miners: an exploration of previously unrecognised determinants. Occup Environ Med 1999:56:837-44.

27 Pollock D, Potts J, Joy G. Investigation in dust exposures and mining practices in mines in the southern Appalachian region. Mining Engineering 2010;62:44-9.

28 Wade W, Petsonk E, Young B, et al. Severe occupational pneumoconiosis among West Virginian coal miners: one hundred thirty-eight cases of progressive massive fibrosis compensated between 2000 and 2009. Chest 2011;139:1458-62.

29 Ford E, Mannino D, Wheaton A, et al. Trends in the prevalence of obstructive and restrictive lung function among adults in the United States. Chest 2013;143:1395-406.

30 Syamlal G, Mazurek J, Malarcher A. Current cigarette smoking prevalence among working adults-United States, 2004-2010. MMWR 2011;60:1305-9.

31 Laney A, Attfield M. Examination of potential sources of bias in the US Coal Workers' Health Surveillance Program. Am J Public Health 2013;104:165-70.

32 U.S. Department of Labor. Lowering Miners' Exposure to Respirable Coal Mine Dust, including Continuous Personal Dust Monitors, Federal Register Volume 79, Number 84. 2014 